\title{
Evaluation criterion for different methods of multiple-attribute group decision making with interval-valued intuitionistic fuzzy information
}

\author{
Junda Qiu ${ }^{1}$, Lei Li ${ }^{2 *}$ \\ ${ }^{1}$ School of Internet of Things Engineering, Jiangnan University, Wuxi, Jiangsu 214122, China \\ ${ }^{2}$ Business School, Jiangnan University, Wuxi, Jiangsu 214122, China \\ [e-mail: inf2007@126.com (L. Lei).] \\ *Corresponding author: Lei Li
}

Received October 20, 2017; revised March 5, 2018; accepted March 14, 2018;

published July 31, 2018

\begin{abstract}
A number of effective methods for multiple-attribute group decision making (MAGDM) with interval-valued intuitionistic fuzzy numbers (IVIFNs) have been proposed in recent years. However, the different methods frequently yield different, even sometimes contradictory, results for the same problem. In this paper a novel criterion to determine the advantages and disadvantages of different methods is proposed. First, the decision-making process is divided into three parts: translation of experts' preferences, aggregation of experts' opinions, and comparison of the alternatives. Experts' preferences aggregation is considered the core step, and the quality of the collective matrix is considered the most important evaluation index for the aggregation methods. Then, methods to calculate the similarity measure, correlation, correlation coefficient, and energy of the intuitionistic fuzzy matrices are proposed, which are employed to evaluate the collective matrix. Thus, the optimal method can be selected by comparing the collective matrices when all the methods yield different results. Finally, a novel approach for aggregating experts' preferences with IVIFN is presented. In this approach, experts' preferences are mapped as points into two-dimensional planes, with the plant growth simulation algorithm (PGSA) being employed to calculate the optimal rally points, which are inversely mapped to IVIFNs to establish the collective matrix. In the study, four different methods are used to address one example problem to illustrate the feasibility and effectiveness of the proposed approach.
\end{abstract}

Keywords: Multiple-attribute group decision making (MAGDM); Interval-valued intuitionistic fuzzy numbers (IVIFN); Collective matrix; Plant growth simulation algorithm (PGSA); Optimal rally point 


\section{Introduction}

$\mathbf{W}_{\text {ith the drastic development of current management science and systems engineering, }}$ many multiple-attribute group decision making (MAGDM) problems have become increasingly complex. Because of their limited knowledge of the research areas related to the problem and lack of relevant information, as well as because of time pressure, experts or decision makers cannot accurately express their opinions. Thus, it is quite difficult or unrealistic to translate experts' preferences into crisp numbers or linguistics. To obtain a more accurate expert preference, many researchers have focused on the study of MAGDM with fuzzy information (such as interval-valued fuzzy numbers (IVFN) and interval-valued intuitionistic fuzzy numbers (IVIFN)). Since then, the IFS and IVIFS have been widely applied to MAGDM problems, because of their effectiveness and veracity in expressing fuzzy information. Wan and Dong developed an interval-valued intuitionistic fuzzy (IVIF) mathematical programming method for hybrid MAGDM that considers alternative comparisons by using hesitancy degrees [1]. Qi, Liang, and Zhang focused on MAGDM with unknown expert and attribute weights under an IVIF environment. In their paper, they proposed a maximizing optimization model to objectively obtain unknown attribute weights, and they developed an integrated algorithm to ascertain unknown expert weights [2]. Ye proposed novel methods using an entropy weights-based correlation coefficient for IFSs and IVIFSs to identify the best alternative among the results for MAGDM problems [3]. Yue proposed several excellent methods for determining the weights of experts in MAGDM based on an extended technique for order preference by similarity to an ideal solution (TOPSIS) [4]. Prakash developed Multi-Attribute Intuitionistic Fuzzy Group Decision Method (MAIFGDM) using TOPSIS for the selection of the suitable candidate network[5]. Liu and Li developed an approach for determining the integrated weights of experts based on interval-valued preference matrices [6]. Practical application of multiple attribute group decision making and fuzzy information can be found in [7-14]

The above methods provide various ideas for addressing MAGDM with IVIFS information. However, different methods always yield different results for the same example. For instance, propose there are five evacuation plans when natural disasters strike and results aggregated by different methods are contradictory, then a useful evaluation criterion can select the best alternative fleetly. However, to the best of our knowledge, thus far little attention has been paid to evaluating the advantages and disadvantages of these methods. Therefore, this paper proposes a novel evaluation methodology for various aggregation algorithms. First, the process of group decision making is divided into three stages: translation of experts' preferences, aggregation of experts' opinions (i.e., establishing the collective matrix), and selection of the best alternative. The process of experts' preferences aggregation is the core step in these three parts, because the accuracy rating of the collective matrix embodies the quality of the experts' preferences aggregation. All the methods referenced in this paper are based on the MAGDM under the IVIFS environment and employ an intuitionistic fuzzy weighted arithmetic aggregation (IIFWA) operator to calculate the program score. Thus, the second step of all these methods varies. Then, when the order of the alternatives is different, the correctness of the different methods can be evaluated by comparing the accuracy rating of their collective matrices. This paper proposes novel methods to calculate the total weighted Hamming distance, total similarity measure, total correlation coefficient, and energy of the collective matrix. Then, the accuracies of the different collective matrices established by 
various aggregation methods are obtained. The more accurate the collective matrix, the more effective is the aggregation method. Additionally, a new approach for aggregating experts' preferences with IVIFNs is described in this paper. The IVIFNs of each expert preference matrix are mapped into two-dimensional planes, and thus, the membership degree and non-membership degree of each IVIFS are considered as points in the dimensional plane. Therefore, the aggregation of experts' preferences is converted to point aggregation, and the relationship between two experts' preferences is expressed as the distance between two points. The preference points for the same attribute of the same alternative are considered a point set. The plant growth simulation algorithm (PGSA) is employed to calculate the optimal point, that is, the point the sum of the distances of which to all the other points in its point set is shortest. The optimal point can describe the experts' comprehensive opinion and achieve Pareto optimality in theory. All the optimal points are employed to establish the collective matrix. So that the comparison experiment would be reasonable, an IIFWA operator is used to evaluate alternatives in the collective matrix.

The remainder of this paper is organized as following. Section 2 introduces the preliminaries, including, the IVIFS, the concept of an optimal rally point, and the principles of the PGSA. Section 3 presents the concept of the evaluation criterion in detail and focuses on the calculation process of the total weighted Hamming distance, total similarity measure, total correlation coefficient, and the energy of the collective matrix. Section 4presents the aggregation idea of the proposed aggregation method. Finally, four aggregation methods are employed to handle a practical example in Section 5. The most credible result is selected by applying the proposed evaluation criterion. Section 6 concludes the paper.

\section{Preliminaries}

\subsection{Basic notions of interval-valued intuitionistic fuzz set}

An IVIFS $\tilde{A}$ in a finite universe of discourse $X=\left\{x_{1}, x_{2}, \ldots, x_{n}\right\}$ is an object in the form

$$
\tilde{A}=\left\{\left\langle x, \mu_{\tilde{A}}(x), v_{\tilde{A}}(x)\right\rangle \mid x \in X\right\},
$$

where $\mu_{\tilde{A}}(x):=\left[\mu_{\tilde{A}}^{L}(x), \mu_{\tilde{A}}^{U}(x)\right] \subset[0,1], \quad v_{\tilde{A}}(x):=\left[v_{\tilde{A}}^{L}(x), v_{\tilde{A}}^{U}(x)\right] \subset[0,1]$, and $\mu_{\tilde{A}}^{U}(x)+v_{\tilde{A}}^{U}(x) \leq 1$. The interval numbers, $\mu_{\tilde{A}}(x)$ and $v_{\tilde{A}}(x)$, respectively denote the membership and non-membership degree of $x$ to $\tilde{A}$. Additionally, $\pi_{\tilde{A}}(x)=\left[\pi_{\tilde{A}}^{L}(x), \pi_{\tilde{A}}^{U}(x)\right]$, where $\pi_{\tilde{A}}^{L}(x)=1-\mu_{\tilde{A}}^{U}(x)-v_{\tilde{A}}^{U}(x)$ and $\pi_{\tilde{A}}^{U}(x)=1-\mu_{\tilde{A}}^{L}(x)-v_{\tilde{A}}^{L}(x)$ and. The interval number $\pi_{\tilde{A}}(x)$ is called the degree of indeterminacy of $x$ to $\tilde{A}$. Operation theorems of IVIFSs have been shown in Appendix.

Definition 1. Let $\omega_{i}(1 \leq i \leq n)$ represent the weights of the elements $x_{i} \in X$, which satisfy the normalized conditions $\omega_{i} \in[0,1]$ and $\sum_{i=1}^{n} \omega_{i}=1$. Wan and Dong defined the weighted Minkowski distance between IVIFSs $\tilde{A}$ and $\tilde{B}$ as 


$$
\begin{aligned}
d_{q}(\tilde{A}, \tilde{B})= & {\left[\frac { 1 } { 4 } \sum _ { i = 1 } ^ { n } \omega _ { i } \left(\left|\mu_{\tilde{A}}^{L}(x)-\mu_{\tilde{B}}^{L}(x)\right|^{q}+\left|\mu_{\tilde{A}}^{U}(x)-\mu_{\tilde{B}}^{U}(x)\right|^{q}\right.\right.} \\
& +\left|v_{\tilde{A}}^{L}(x)-v_{\tilde{B}}^{L}(x)\right|^{q}+\left|v_{\tilde{A}}^{U}(x)-v_{\tilde{B}}^{U}(x)\right|^{q} \\
& \left.\left.+\left|\pi_{\tilde{A}}^{L}(x)-\pi_{\tilde{B}}^{L}(x)\right|^{q}+\left|\pi_{\tilde{A}}^{U}(x)-\pi_{\tilde{B}}^{U}(x)\right|^{q}\right)\right]^{1 / q} .
\end{aligned}
$$

When $q=1, q=2$, and $q \rightarrow+\infty \quad$, the corresponding $\quad d_{1}(\tilde{A}, \tilde{B}), d_{2}(\tilde{A}, \tilde{B})$, and $d_{+\infty}(\tilde{A}, \tilde{B})$ represent the weighted Hamming, Euclidean, and Chebyshev distances, respectively [15].

Definition 2.Xu and Chen defined a similarity measure that combines the distance measures of the IFSs $A=\left(\mu_{A}, v_{A}\right)$ and $B=\left(\mu_{B}, v_{B}\right)$ :

$$
S(A, B)=\frac{d\left(A, B^{c}\right)}{d(A, B)+d\left(A, B^{c}\right)}, \quad A, B \in \operatorname{IFS}(X) .
$$

where $B^{c}=\left(v_{B}, \mu_{B}\right), 0 \leq S(A, B) \leq 1$. In particular, if $A=B$, then $S(A, B)=1$ [16].

Similarly, the following equation defines the weighted similarity measure of IVIFSs $\tilde{A}$ and $\tilde{B}$ :

$$
S(\tilde{A}, \tilde{B})=\frac{d_{1}\left(\tilde{A}, \tilde{B}^{c}\right)}{d_{1}(\tilde{A}, \tilde{B})+d_{1}\left(\tilde{A}, \tilde{B}^{c}\right)} \quad \tilde{A}, \tilde{B} \in \operatorname{IVIFS}(X) .
$$

For $\tilde{A}, \tilde{B}, \tilde{C} \in \operatorname{IVIFS}(X)$, the similarity measure satisfies

(S1) $S(\tilde{A}, \tilde{B})=0 \Leftrightarrow \tilde{A}=\tilde{B}^{c}$;

(S2) $S(\tilde{A}, \tilde{B})=1 \Leftrightarrow \tilde{A}=\tilde{B}$;

(S3) $S(\tilde{A}, \tilde{B})=S(\tilde{B}, \tilde{A})$;

(S4) for all $\tilde{A}, \tilde{B}, \tilde{C} \in \operatorname{IVIFS}(X)$, if $\tilde{A} \subseteq \tilde{B} \subseteq \tilde{C}$, then $S(\tilde{A}, \tilde{C}) \leq S(\tilde{A}, \tilde{B}), S(\tilde{A}, \tilde{C}) \leq S(\tilde{B}, \tilde{C})$.

Definition 3.Bustince and Burillo [17] defined the correlation of $\tilde{A}, \tilde{B} \in \operatorname{IVIFSs}(X)$ as

$$
\begin{aligned}
& C(\tilde{A}, \tilde{B})= \\
& \frac{1}{2}\left(\sum_{i=1}^{n} \mu_{\tilde{A}}^{L}\left(x_{i}\right) \mu_{\tilde{B}}^{L}\left(x_{i}\right)+\mu_{\tilde{A}}^{U}\left(x_{i}\right) \mu_{\tilde{B}}^{U}\left(x_{i}\right)+v_{\tilde{A}}^{L}\left(x_{i}\right) v_{\tilde{B}}^{L}\left(x_{i}\right)+v_{\tilde{A}}^{U}\left(x_{i}\right) v_{\tilde{B}}^{U}\left(x_{i}\right)\right),\left(x_{i} \in X\right),
\end{aligned}
$$

and defined the correlation coefficient between $\tilde{A}$ and $\tilde{B}$ by

$$
K(\tilde{A}, \tilde{B})=\frac{C(\tilde{A}, \tilde{B})}{\sqrt{C(\tilde{A}, \tilde{A}) \cdot C(\tilde{B}, \tilde{B})}} .
$$

For $\tilde{A}, \tilde{B} \in \operatorname{IVIFS}(X)$, the correlation coefficient satisfies 
(K1) if $\tilde{A}=\tilde{B}$, then $K(\tilde{A}, \tilde{B})=1$;

$(\mathrm{K} 2) K(\tilde{A}, \tilde{B})=K(\tilde{B}, \tilde{A})$;

(K3) $0 \leq K(\tilde{A}, \tilde{B}) \leq 1$;

Definition 4.Park and Kwun [18] defined the informational intuitionistic energy of each $\tilde{A} \in \operatorname{IVIFS}(X)$ as

$$
\begin{aligned}
& E(\tilde{A})= \\
& \sum_{i=1}^{n} \frac{\left(\mu_{\tilde{A}}^{L}\left(x_{i}\right)\right)^{2}+\left(\mu_{\tilde{A}}^{U}\left(x_{i}\right)\right)^{2}+\left(v_{\tilde{A}}^{L}\left(x_{i}\right)\right)^{2}+\left(v_{\tilde{A}}^{U}\left(x_{i}\right)\right)^{2}+\left(\pi_{\tilde{A}}^{L}\left(x_{i}\right)\right)^{2}+\left(\pi_{\tilde{A}}^{U}\left(x_{i}\right)\right)^{2}}{2}
\end{aligned}
$$

where $\left(x_{i} \in X\right)$.

For $\tilde{A}, \tilde{B} \in \operatorname{IVIFS}(X)$, the function $E$ satisfies the conditions

(E1) $E(\tilde{A})=E\left(\tilde{A}^{c}\right)$ for all $\tilde{A} \in \operatorname{IVIFS}(X)$;

(E2) $E(\tilde{A}) \leq n$ for all $\tilde{A} \in \operatorname{IVIFS}(X)$;

(E3) $E(\tilde{A}) \leq E(\tilde{B})$ if $\tilde{A}$ is less fuzzy then $\tilde{B}$.

Definition 5.Xu first proposed the IIFWA operator. Let $\tilde{\alpha}_{j}=\left(\left[a_{j}, b_{j}\right],\left[c_{j}, d_{j}\right]\right)(1 \leq j \leq n)$ be a collection of IVIFNs, and let IIFWA: $\tilde{\Theta}^{n} \rightarrow \tilde{\Theta}$.If

$$
\begin{aligned}
& \operatorname{IIFWA}_{\omega}\left(\tilde{\alpha}_{1}, \tilde{\alpha}_{2}, \cdots, \tilde{\alpha}_{n}\right)=\omega_{1} \tilde{\alpha}_{1} \oplus \omega_{2} \tilde{\alpha}_{2} \oplus \cdots \oplus \omega_{n} \tilde{\alpha}_{n} \\
& =\left(\left[1-\prod_{j=1}^{n}\left(1-a_{j}\right)^{\omega_{j}}, 1-\prod_{j=1}^{n}\left(1-b_{j}\right)^{\omega_{j}}\right],\left[\prod_{j=1}^{n} c_{j}^{\omega_{j}}, \prod_{j=1}^{n} d_{j}^{\omega_{j}}\right]\right),
\end{aligned}
$$

then IIFWA is called an IVIF weighted averaging operator of dimension $n$, where $\omega=\left(\omega_{1}, \omega_{2}, \cdots, \omega_{n}\right)^{\mathrm{T}}$ is the weight vector of $\tilde{\alpha}_{j}(1 \leq j \leq n)$, with $\omega_{j} \in[0,1]$, and $\sum_{j=1}^{n} \omega_{j}=1$.

Let $\tilde{\alpha}=([a, b],[c, d])$ be an IVIFN; then,

$$
s(\tilde{\alpha})=\frac{1}{2}(a-c+b-d)
$$

is a score of $\tilde{\alpha}$, where $s(\tilde{\alpha}) \in[-1,1]$. The larger the score $s(\tilde{\alpha})$, the greater is the IVIFN $\tilde{\alpha}[19]$.

\subsection{Multiple-attribute group decision making with interval-valued intuitionistic fuzzy preference information}

In the MAGDM problem, a number of experts are involved to evaluate several alternatives with multiple attributes. Because of their time pressure and lack of information and personal willingness, experts cannot easily provide an accurate assessment of the information. Thus, it is unreasonable to express experts' preferences by a crisp number. Therefore, many researchers focused on the MAGDM with IVIF preference information. 
Suppose there are $k$ experts applying interval-valued intuitionistic numbers $\tilde{d}_{i j}^{t}(1 \leq t \leq k)$ to evaluate the $i$ th alternative with the $j$ th characteristic; then, the expert preference matrices $\left[\tilde{D}_{t}\right]$ are constructed as

$$
\begin{aligned}
& {\left[\tilde{D}_{t}\right]=\left[\tilde{d}_{i j}^{t}\right]_{i \times j}=} \\
& \left(\begin{array}{ccc}
\left(\left[\mu_{11}^{L}, \mu_{11}^{U}\right],\left[v_{11}^{L}, v_{11}^{U}\right]\right) & \cdots & \left(\left[\mu_{1 j}^{L}, \mu_{1 j}^{U}\right],\left[v_{1 j}^{L}, v_{1 j}^{U}\right]\right) \\
\vdots & \ddots & \vdots \\
\left(\left[\mu_{i 1}^{L}, \mu_{i 1}^{U}\right],\left[v_{i 1}^{L}, v_{i 1}^{U}\right]\right) & \cdots & \left(\left[\mu_{i j}^{L}, \mu_{i j}^{U}\right],\left[v_{i j}^{L}, v_{i j}^{U}\right]\right)
\end{array}\right) .
\end{aligned}
$$

Different authors employ their own methods, such as an interval-valued intuitionistic fuzzy hybrid aggregation(IIFHA) operator, projection method, IIFHG operator, and MULTIMOORA method, to construct the collective matrix. The collective matrix $[\dot{D}]$ can comprehensively reflect experts' preferences, and is given by

$$
[\dot{D}]=\left[\dot{d}_{i j}\right]_{i \times j}=\left(\begin{array}{ccc}
\left(\dot{\mu}_{11}, \dot{v}_{11}\right) & \ldots & \left(\dot{\mu}_{1 j}, \dot{v}_{1 j}\right) \\
\vdots & \ddots & \vdots \\
\left(\dot{\mu}_{i 1}, \dot{v}_{i 1}\right) & \cdots & \left(\dot{\mu}_{i j}, \dot{v}_{i j}\right)
\end{array}\right) .
$$

In this study, PGSA is employed to calculate the optimal rally point first. Then, the optimal aggregation points of all point sets are used to establish the collective matrix.

\subsection{Optimal rally point}

Definition 6.Let $P=\left\{P_{1}, P_{2}, \ldots, P_{n}\right\} \quad(n \geq 3)$ be a point set in a bounded closed box in a two-dimensional plane. $P_{i}(1 \leq i \leq n)$ is a weighted point, the corresponding positive weights of which are $\xi_{i} \in[0,1]$, and $\sum_{i=1}^{n} \xi_{i}=1$. If a point $P^{*}$ exists, the Euclidean distances of which to the other given points meet the condition

$$
D=\min \sum_{i=1}^{n}\left|P^{*} P_{i}\right|=\min \left(\sqrt{\left(x^{*}-a_{1}\right)^{2}+\left(y^{*}-b_{1}\right)^{2}}+\cdots+\sqrt{\left(x^{*}-a_{n}\right)^{2}+\left(y^{*}-b_{n}\right)^{2}}\right),
$$

then we define $P^{*}$ as the optimal rally point (see Fig. 1).

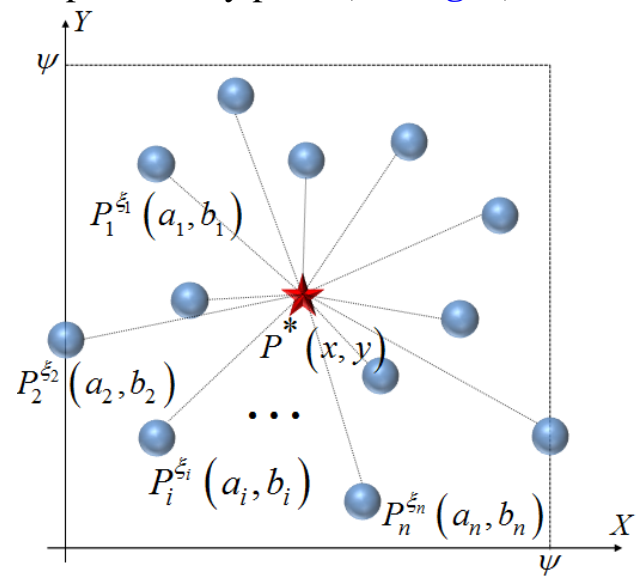

Fig. 1. Optimal rally point 
The optimal rally point achieves Pareto optimality. In this study, experts' preferences are mapped as points into the two-dimensional plane, thus allowing the distance between two points to be expressed by the degree of similarity between two experts' preferences. In our method, we aggregate experts' preferences by calculating the optimal rally point. Then, we establish the collective matrix by inverse mapping the optimal rally point.

With the increment of points on the plane, the difficulty for searching the optimal rally point grows exponentially. In this study, a plant growth simulation algorithm (PGSA) is used to solve this problem.

\subsection{Plant growth simulation algorithm (PGSA)}

The PGSA, a heuristic algorithm based on the plant growth mechanism, is first proposed by a Chinese scholar, Li. It is less sensitive to parameter sets and its data are not needed for coding and decoding. The PGSA has been widely applied in numerous fields, such as distribution system optimization planning, facility location, transmission network optimal planning, optimal capacitor placement, and RFID network planning[20-24], because of its accuracy, high-efficiency, and flexibility.

\subsubsection{Principles of plant growth}

Most plants are phototropic. Many nodes exist on the trunk and a new branch always grows from a node that is located toward the sun. The closer their location to the sun, the higher the morphactin concentration of the branches, and branches having a higher morphactin concentration have a greater opportunity to have a new growth node. This growth mechanism is repeated until the plant is fully formed. The morphactin concentration distribution and the process of plant growth are shown in Fig. 2 and Fig. 3, respectively.

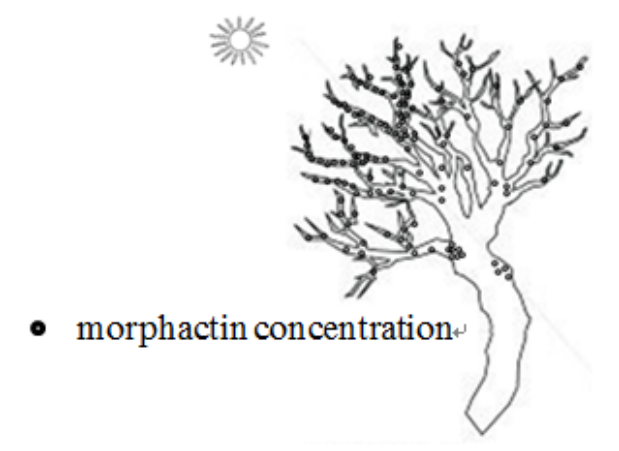

Fig. 2. Morphactin concentration distribution

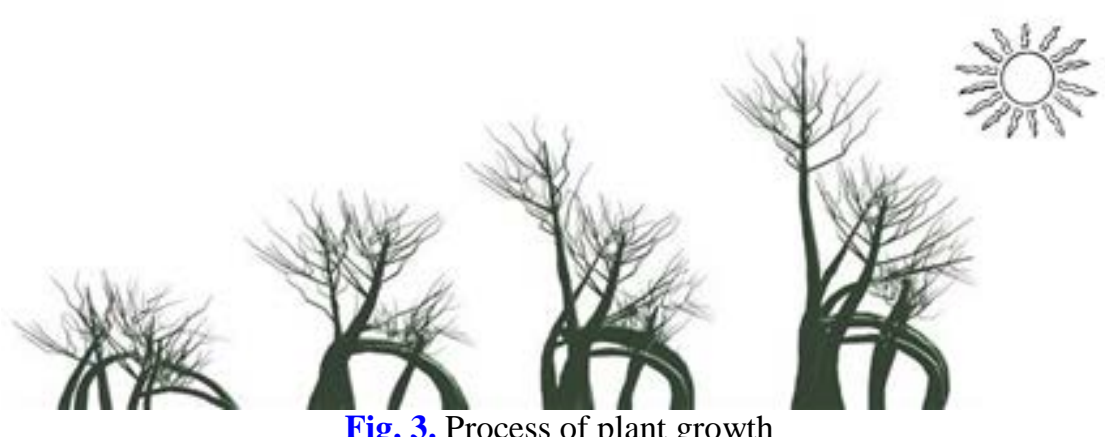

Fig. 3. Process of plant growth 
Additionally, the morphactin concentration of each node and branch in the plant is updated as the new stems grow. During the entire growth process, the morphactin concentration of each branch is determined by the environmental information of the node from which it grows; it depends on the branch's relative position on the plant and is not determined in advance.

\subsubsection{Probabilistic model of plant growth simulation algorithm}

The entire growing space of the plant is regarded as a feasible domain in the probabilistic model of PGSA. The point closest to the light source is the global optimum point. The procedure for searching the optimal point is the same as the process of plant growth. First, one point,x0, is randomly selected as the root and the trunk $M$ grows from it. Suppose there are $t$ nodes, $S_{M 1}, S_{M 2}, \ldots, S_{M t}$, on the trunk having growth hormone concentrations $C_{M 1}, C_{M 2}, \ldots, C_{M t}$. $C_{M i}(1 \leq i \leq t)$ is given by

$$
C_{M i}=\frac{f\left(x^{0}\right)-f\left(S_{M i}\right)}{\sum_{i=1}^{t}\left(f\left(x^{0}\right)-f\left(S_{M i}\right)\right)} \quad(1 \leq i \leq t),
$$

where $f\left(x^{0}\right)$ is the backlight function for describing the environment of point $x_{0}$. The shorter the distance between $X$ and the light source, the smaller the value of $f\left(x^{0}\right)$. The function value decreases as the illumination of the growth node increases.

$\sum_{i=1}^{t} C_{M i}=1$ is clearly derived from Eq. (12). Then, a special roulette (see Fig. 4) is established according to this feature. Thus, this roulette can be employed to select a new growth node.

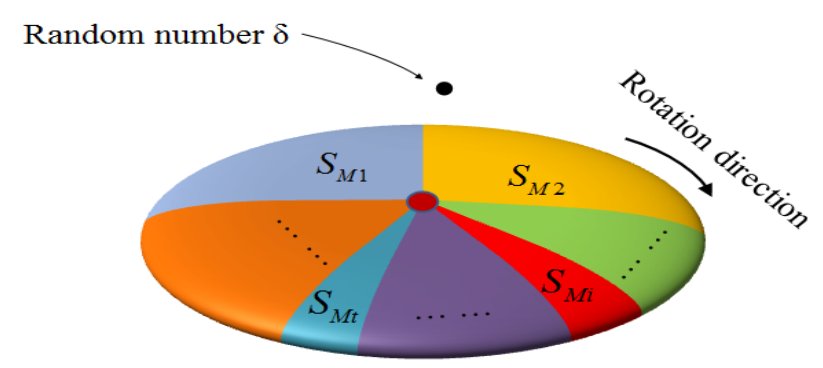

Fig. 4. Special roulette

The node $S_{M i}$ occupies its own area on the roulette. A random number $\delta$ is selected in the interval [0,1],a method that is similar to throwing a ball onto a state map. It will land in the area of one of $S_{M 1}, S_{M 2}, \ldots, S_{M t}$. The corresponding node $S_{M k}(1 \leq k \leq t)$, which is the preferential growth node, will take priority to grow a new branch in the next step.

It is assumed that a new branch $\mathrm{m}$ grows from $S_{M k}$, which has $\mathrm{r}$ nodes, namely, $S_{m 1}, S_{m 2}, \ldots, S_{m r}$. The growth hormone concentrations of the nodes on branch mare $C_{m 1}, C_{m 2}, \ldots, C_{m r}$. According to the principle of plant growth, the morphactin concentration of each node in the plant is updated after each new round of branch growth. After branch $m$ has grown, the concentrations of the nodes on trunk $M$ (except $\mathrm{S}_{M k}$ ) and branch $\mathrm{m}$ need to be recalculated. Meanwhile, $\mathrm{C}_{M i}$ and $\mathrm{C}_{m j}$ can be calculated by 


$$
\left\{\begin{array}{l}
C_{M i}=\frac{f\left(x^{0}\right)-f\left(S_{M i}\right)}{\sum_{i=1}^{t}\left(f\left(x^{0}\right)-f\left(S_{M i}\right)\right)+\sum_{j=1}^{r}\left(f\left(x^{0}\right)-f\left(S_{n j}\right)\right)} \\
C_{m j}=\frac{f\left(x^{0}\right)-f\left(S_{n j}\right)}{\sum_{i=1}^{t}\left(f\left(x^{0}\right)-f\left(S_{M i}\right)\right)+\sum_{j=1}^{r}\left(f\left(x^{0}\right)-f\left(S_{n j}\right)\right)}
\end{array} \quad(1 \leq i \leq t, 1 \leq j \leq r, i \neq k)\right.
$$

$\sum_{i=1, i \neq k}^{t} C_{M i}+\sum_{j=1}^{r} C_{m j}=1$ can evidently be derived from Eq. (13). A new roulette is established as in the previous step. All the nodes on trunk $M$ (except $\mathrm{S}_{M k}$ ) and branch $m$ respectively occupy their own range on the roulette, one among which is selected as the new growth point for a new branch.

The growth process is repeated until the new branch reaches the optimal point. The PGSA cannot easily fall into local optimum, because the morphactin concentrations of all nodes are updated during each growth step.

\section{Evaluation criteria}

MAGDM with IVIF information is investigated in this study. Each expert's preferences are described as IVIF matrices. Through the aggregation of expert preference matrices, various aggregation methods always yield a different collective matrix (see Fig. 5).The quality of the collective matrix has a strong influence on the result. This section focuses on the relationship and distance among IVIF matrices. In addition, a novel method for evaluating a collective matrix is proposed.

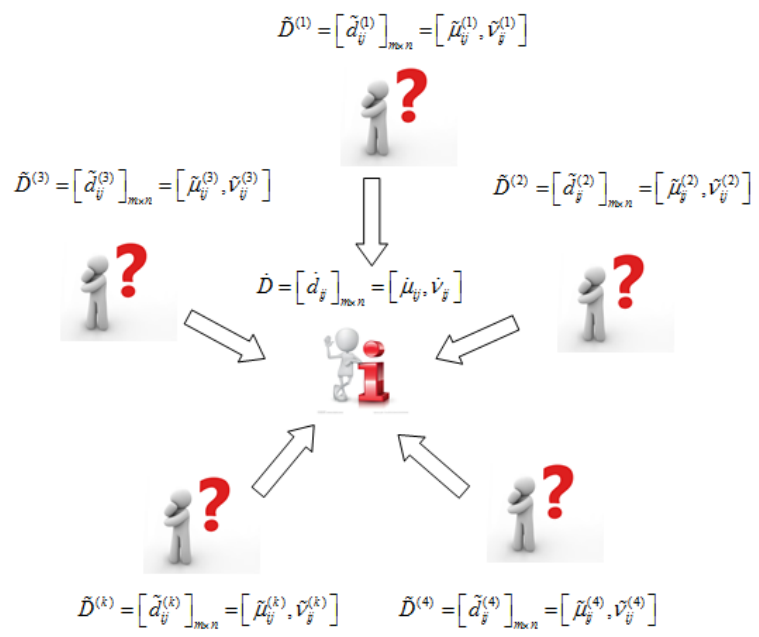

Fig. 5. Establishmentof the collective matrix

Let us examine Eq. (1).The weighted Hamming distance between IVIF matrices is defined as $\tilde{D}_{1_{m \times n}}=\left(\tilde{d}_{i j}^{(1)}\right)_{m \times n}=\left(\left(\left[\mu_{i j}^{(1) L}, \mu_{i j}^{(1) U}\right],\left[v_{i j}^{(1) L}, v_{i j}^{(1) U}\right]\right)\right)_{m \times n}$ and $\tilde{D}_{2_{m \times n}}=\left(\tilde{d}_{i j}^{(2)}\right)_{m \times n}=\left(\left(\left[\mu_{i j}^{(2) L}, \mu_{i j}^{(2) U}\right],\left[v_{i j}^{(2) L}, v_{i j}^{(2) U}\right]\right)\right)_{m \times n}$ and 


$$
\begin{array}{r}
d\left(\tilde{D}_{1_{\operatorname{m\times n}}}, \tilde{D}_{2_{\text {mxn }}}\right)=\frac{1}{4} \sum_{i=1}^{m} \sum_{j=1}^{n} \delta_{i j}\left(\left|\mu_{i j}^{(1) L}(x)-\mu_{i j}^{(2) L}(x)\right|+\left|\mu_{i j}^{(1) U}(x)-\mu_{i j}^{(2) U}(x)\right|\right. \\
+\left|v_{i j}^{(1) L}(x)-v_{i j}^{(2) L}(x)\right|+\left|v_{i j}^{(1) U}(x)-v_{i j}^{(2) U}(x)\right| \\
\left.+\quad\left|\pi_{i j}^{(1) L}(x)-\pi_{i j}^{(2) L}(x)\right|+\left|\pi_{i j}^{(1) U}(x)-\pi_{i j}^{(2) U}(x)\right|\right)
\end{array}
$$

where $\delta_{i j}(1 \leq i \leq m, 1 \leq j \leq n)$ represents the weight elements $\tilde{d}_{i j}^{(k)} \in \tilde{D}_{k}$, which satisfy the normalized conditions $\delta_{i j} \in[0,1]$ and $\sum_{i=1}^{m} \sum_{j=1}^{n} \delta_{i j}=1$.

Similarly to Eq. (3), the following equation defines the similarity measure between $\tilde{D}_{1_{m \times n}}$ and $\tilde{D}_{2_{m \times n}}$ :

$$
\begin{aligned}
S\left(\tilde{D}_{1_{m \times n}}, \tilde{D}_{2_{m \times n}}\right) & =\frac{d\left(\tilde{D}_{1_{m \times n}}, \tilde{D}_{2_{m \times n}}^{c}\right)}{d\left(\tilde{D}_{1_{m \times n}}, \tilde{D}_{2_{m \times n}}\right)+d\left(\tilde{D}_{1_{m \times n}}, \tilde{D}_{2_{m \times n}}^{c}\right)} \\
& =\frac{\sum_{i=1}^{m} \sum_{j=1}^{n} d\left(\tilde{d}_{i j}^{(1)},\left(\tilde{d}_{i j}^{(2)}\right)^{c}\right)}{\sum_{i=1}^{m} \sum_{j=1}^{n}\left(d\left(\tilde{d}_{i j}^{(1)}, \tilde{d}_{i j}^{(2)}\right)+d\left(\tilde{d}_{i j}^{(1)},\left(\tilde{d}_{i j}^{(2)}\right)^{c}\right)\right)} .
\end{aligned}
$$

The closer the two matrices, the more similar they will be.

Let $\tilde{D}_{1_{m \times n}}, \tilde{D}_{2_{m \times n}}$ and $\tilde{D}_{3_{m \times n}}$ be intuitionistic fuzzy matrices. The similarity measure satisfies

$\left(\mathrm{S} 1^{\prime}\right) S\left(\tilde{D}_{1_{m \times n}}, \tilde{D}_{2_{m \times n}}\right)=0 \Leftrightarrow \tilde{D}_{1_{m \times n}}=\tilde{D}_{2_{m \times n}}^{c}$;

$\left(\mathrm{S} 2^{\prime}\right) S\left(\tilde{D}_{1_{m \times n}}, \tilde{D}_{2_{m \times n}}\right)=1 \Leftrightarrow \tilde{D}_{1_{m \times n}}=\tilde{D}_{2_{m \times n}}$;

$\left(\mathrm{S} 3^{\prime}\right) S\left(\tilde{D}_{1_{m \times n}}, \tilde{D}_{2_{m \times n}}\right)=S\left(\tilde{D}_{2_{m \times n}}, \tilde{D}_{1_{m \times n}}\right)$;

$\left(\mathrm{S} 4^{\prime}\right) \tilde{D}_{1_{m \times n}} \subseteq \tilde{D}_{2_{m \times n}} \subseteq \tilde{D}_{3_{m \times n}}$, then $S\left(\tilde{D}_{1_{m \times n}}, \tilde{D}_{3_{m \times n}}\right) \leq S\left(\tilde{D}_{1_{m \times n}}, \tilde{D}_{2_{m \times n}}\right), S\left(\tilde{D}_{1_{m \times n}}, \tilde{D}_{3_{m \times n}}\right) \leq S\left(\tilde{D}_{2_{m \times n}}, \tilde{D}_{3_{m \times n}}\right)$.

In this paper, we propose the correlation $C\left(\tilde{D}_{1_{m \times n}}, \tilde{D}_{2_{m \times n}}\right)$ and correlation

coefficient $K\left(\tilde{D}_{1_{m \times n}}, \tilde{D}_{2_{m \times n}}\right)$ between $\tilde{D}_{1_{m \times n}}$ and $\tilde{D}_{2_{m \times n}}$ as

$$
\begin{aligned}
& C\left(\tilde{D}_{1_{m \times n}}, \tilde{D}_{2_{m \times n}}\right)= \\
& \frac{1}{2}\left(\sum_{i=1}^{m} \sum_{j=1}^{n} \mu_{i j}^{(1) L}(x) \mu_{i j}^{(2) L}(x)+\mu_{i j}^{(1) U}(x) \mu_{i j}^{(2) U}(x)+v_{i j}^{(1) L}(x) v_{i j}^{(2) L}(x)+v_{i j}^{(1) U}(x) v_{i j}^{(2) U}(x)\right) \\
& K\left(\tilde{D}_{1_{m \times n}}, \tilde{D}_{2_{m \times n}}\right)=\frac{C\left(\tilde{D}_{1_{m \times n}}, \tilde{D}_{2_{m \times n}}\right)}{\sqrt{C\left(\tilde{D}_{1_{m \times n}}, \tilde{D}_{1_{m \times n}}\right) \cdot C\left(\tilde{D}_{2_{m \times n}}, \tilde{D}_{2_{m \times n}}\right)}}
\end{aligned}
$$

These equations are similar to Eqs. (4) and (5).

Let $\tilde{D}_{1_{m \times n}}$ and $\tilde{D}_{2_{m \times n}}$ be two intuitionistic fuzzy matrices. The correlation coefficient satisfies the following. 
(K1') if $\tilde{D}_{1_{m \times n}}=\tilde{D}_{2_{m \times n}}$, then $K\left(\tilde{D}_{1_{m \times n}}, \tilde{D}_{2_{m \times n}}\right)=1$;

$\left(\mathrm{K2} 2^{\prime}\right) K\left(\tilde{D}_{1_{m \times x}}, \tilde{D}_{2_{\operatorname{mxn}}}\right)=K\left(\tilde{D}_{2_{\operatorname{mxn}}}, \tilde{D}_{1_{\operatorname{mxn}}}\right)$;

(K3') $0 \leq K\left(\tilde{D}_{1_{m \times n}}, \tilde{D}_{2_{m \times n}}\right) \leq 1$.

Let us examine Eq. (6).This paper provides the calculation of energy $E\left(\tilde{D}_{1_{m \times n}}\right)$ of intuitionistic fuzzy matrix $\tilde{D}_{1}$ :

$$
\begin{aligned}
& E\left(\tilde{D}_{1_{m \times n}}\right)= \\
& \sum_{i=1}^{m} \sum_{j=1}^{n} \frac{\left(\mu_{i j}^{L}(x)\right)^{2}+\left(\mu_{i j}^{U}(x)\right)^{2}+\left(v_{i j}^{L}(x)\right)^{2}+\left(v_{i j}^{U}(x)\right)^{2}+\left(\pi_{i j}^{L}(x)\right)^{2}+\left(\pi_{i j}^{U}(x)\right)^{2}}{2}
\end{aligned}
$$

For intuitionistic fuzzy matrices $\tilde{D}_{1_{m \times n}}$ and $\tilde{D}_{2_{m \times x}}$, the energy satisfies the following conditions.

$\left(\mathrm{E} 1^{\prime}\right) E\left(\tilde{D}_{1_{m \times n}}\right)=E\left(\tilde{D}_{1_{m \times n}}^{c}\right)$;

$\left(\mathrm{E} 2^{\prime}\right) E\left(\tilde{D}_{1_{m \times n}}\right) \leq n$;

$\left(\mathrm{E} 3^{\prime}\right) E\left(\tilde{D}_{1_{m \times n}}\right) \leq E\left(\tilde{D}_{2_{m \times n}}\right)$ if $\tilde{D}_{1_{m \times n}}$ is less fuzzy than $\tilde{D}_{2_{m \times n}}$.

The various aggregation methods always yield a different collective intuitionistic fuzzy matrix $\dot{D}_{m \times n}$.In this study, we comparatively evaluated their qualities by calculating the similarity measure, correlation coefficient, and energy of all the experts' preferences matrices.

Let $\tilde{D}_{t_{m \times n}}=\left(\tilde{d}_{i j}^{t}\right)=\left(\left(\left[\mu_{i j}^{t L}, \mu_{i j}^{t U}\right],\left[v_{i j}^{t L}, v_{i j}^{t U}\right]\right)\right)(1 \leq i \leq m, 1 \leq j \leq n, 1 \leq t \leq k)$ be the preferences matrices proposed by $\mathrm{k}$ experts, $\hat{d}\left(\dot{D}_{m \times n}\right), \hat{S}\left(\dot{D}_{m \times n}\right)$, and $\hat{K}\left(\dot{D}_{m \times n}\right)$ be the total weighted Hamming distance, total similarity measure, and total correlation coefficient, respectively, of $\dot{D}_{m \times n}$, and $E\left(\dot{D}_{m \times n}\right)$ be the energy of $\dot{D}_{m \times n}$. Then, $\hat{d}\left(\dot{D}_{m \times n}\right), \hat{S}\left(\dot{D}_{m \times n}\right), \hat{K}\left(\dot{D}_{m \times n}\right)$, and $E\left(\dot{D}_{m \times n}\right)$ can be calculated as

$$
\begin{aligned}
& \hat{d}\left(\dot{D}_{m \times n}\right)=\sum_{t=1}^{k} d\left(\dot{D}_{m \times n}, \tilde{D}_{t_{m \times n}}\right) \\
& \hat{S}\left(\dot{D}_{m \times n}\right)=\sum_{t=1}^{k} S\left(\dot{D}_{m \times n}, \tilde{D}_{t_{m \times n}}\right) \\
& \hat{K}\left(\dot{D}_{m \times n}\right)=\sum_{t=1}^{k} K\left(\dot{D}_{m \times n}, \tilde{D}_{t_{m \times n}}\right) \\
& E\left(\dot{D}_{m \times n}\right)= \\
& \sum_{i=1}^{m} \sum_{j=1}^{n} \frac{\left(\dot{\mu}_{i j}^{L}(x)\right)^{2}+\left(\dot{\mu}_{i j}^{U}(x)\right)^{2}+\left(\dot{v}_{i j}^{L}(x)\right)^{2}+\left(\dot{v}_{i j}^{U}(x)\right)^{2}+\left(\dot{\pi}_{i j}^{L}(x)\right)^{2}+\left(\dot{\pi}_{i j}^{U}(x)\right)^{2}}{2}(2)
\end{aligned}
$$

Greater values of $\hat{S}\left(\dot{D}_{m \times n}\right)$ and $\hat{K}\left(\dot{D}_{m \times n}\right)$ indicate a higher quality of the collective matrix $\dot{D}_{m \times n}$. A smaller value of $E\left(\dot{D}_{m \times n}\right)$ indicates a less fuzzy degree of $\dot{D}_{m \times n}$. The accuracy of different aggregation methods can be evaluated by comparing $\hat{S}\left(\dot{D}_{m \times n}\right), \hat{K}\left(\dot{D}_{m \times n}\right)$, and $E\left(\dot{D}_{m \times n}\right)$, when they yield different orders of programs.

For instance, two aggregation methods are employed to solve the same MAGDM with 
IVIFSs. Different operators are employed to establish the collective matrix $\dot{D}_{m \times n}$. Method A finally yielded the order of five programs, $Y_{1}-Y_{5}$, as $Y_{3} \succ Y_{5} \succ Y_{2} \succ Y_{4} \succ Y_{1}$, and Method B yielded $Y_{1} \succ Y_{2} \succ Y_{3} \succ Y_{4} \succ Y_{5}$. Then, the more reliable result can be obtained by using the following criteria.

(C1): $\hat{S}_{A}\left(\dot{D}_{m \times n}\right)>\hat{S}_{B}\left(\dot{D}_{m \times n}\right), \hat{K}_{A}\left(\dot{D}_{m \times n}\right)>\hat{K}_{B}\left(\dot{D}_{m \times n}\right)$ and $E_{A}\left(\dot{D}_{m \times n}\right)<E_{B}\left(\dot{D}_{m \times n}\right)$

$\Rightarrow \mathrm{A}$ is much more accurate than $\mathrm{B}$;

(C2): $\left|\hat{S}_{A}\left(\dot{D}_{m \times n}\right)-\hat{S}_{B}\left(\dot{D}_{m \times n}\right)\right|-\left|\hat{K}_{A}\left(\dot{D}_{m \times n}\right)-\hat{K}_{B}\left(\dot{D}_{m \times n}\right)\right|>0$ and $E_{A}\left(\dot{D}_{m \times n}\right)<E_{B}\left(\dot{D}_{m \times n}\right)$

$\Rightarrow \mathrm{A}$ is more accurate than $\mathrm{B}$;

(C3): $\left|\hat{S}_{A}\left(\dot{D}_{m \times n}\right)-\hat{S}_{B}\left(\dot{D}_{m \times n}\right)\right|-\left|\hat{K}_{A}\left(\dot{D}_{m \times n}\right)-\hat{K}_{B}\left(\dot{D}_{m \times n}\right)\right|>0$ and $E_{A}\left(\dot{D}_{m \times n}\right)>E_{B}\left(\dot{D}_{m \times n}\right)$

$\Rightarrow \mathrm{A}$ is slightly more accurate than $\mathrm{B}$;

(C4): $\hat{S}_{A}\left(\dot{D}_{m \times n}\right)>\hat{S}_{B}\left(\dot{D}_{m \times n}\right), \hat{K}_{A}\left(\dot{D}_{m \times n}\right)>\hat{K}_{B}\left(\dot{D}_{m \times n}\right)$ and $E_{A}\left(\dot{D}_{m \times n}\right)>E_{B}\left(\dot{D}_{m \times n}\right)$

$\Rightarrow \mathrm{A}$ is slightly more accurate than $\mathrm{B}$, while $\mathrm{B}$ is less fuzzy than A.

\section{Proposed algorithm}

This study employed PGSA to establish the collective matrix for MAGDM with IVIFSs. The aggregation idea and core steps of the proposed algorithm are introduced in this section.

\subsection{Aggregation idea}

In MAGDM, the preference information of thetth $(1<t<k)$ expert can be expressed by the matrix

$$
D^{(t)}=\left[d_{i j}^{(t)}\right]_{m \times n}, 1 \leq i \leq m ; 1 \leq j \leq n ; 1 \leq t \leq k .
$$

The expert preference is expressed by an IVFN. Equation (21) can be expressed as

$$
\begin{aligned}
D^{(t)} & =\left[d_{i j}^{(t)}\right]_{m \times n}=\left[\mu_{i j}^{(t)}, v_{i j}^{(t)}\right] \\
& =\left[\left(\mu_{i j}^{(t) L}, \mu_{i j}^{(t) U}\right),\left(v_{i j}^{(t) L}, v_{i j}^{(t) U}\right)\right], 1 \leq i \leq m ; 1 \leq j \leq n ; 1 \leq t \leq k
\end{aligned}
$$

We establish two two-coordinates to aggregate membership degree information and non-membership degree information, respectively. As can be seen in Fig. 6(a), the membership degree interval-valued numbers of characteristic C1 in alternative A1 $\mu_{11}^{(k)}$ proposed by $\mathrm{k}$ experts are projected into a two-dimensional coordinate, where $\mu^{L}(x)$ is considered to be the abscissa axis and $\mu^{U}(x)$ is considered to be the vertical axis. Fig. 6(a) shows that non-membership degree interval-valued numbers $v_{11}^{(k)}$ can also be projected. The membership degree optimal rally point $\dot{\mu}_{11}$ and the non-membership degree optimal rally point $\dot{v}_{11}$ can be determined by using PGSA (see Fig. 6(a) and 6(b)). From the inverse mapping relationship, the coordinate value of the optimal rally point can be translated easily into the interval-valued number of aggregation preference information. 


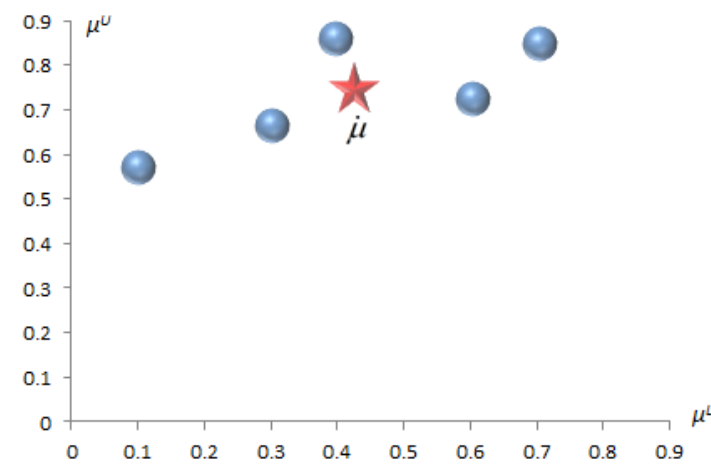

Fig. 6(a). Membership degree coordinate

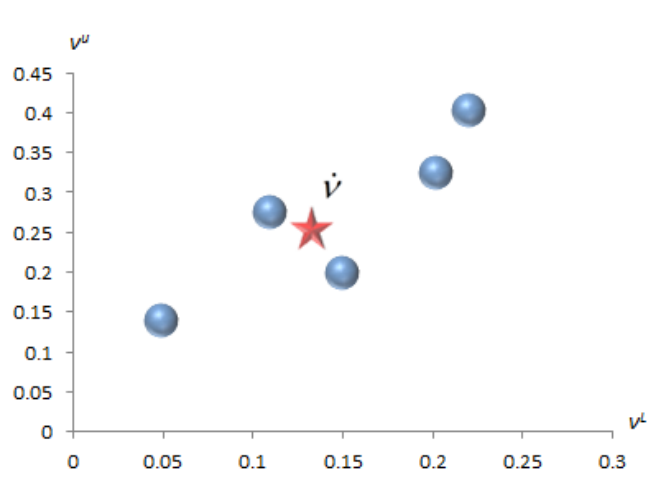

Fig. 6(b). Non-membership degree coordinate

This method is used to find the optimal rally point of all the expert preferences and obtain the expert preference aggregation matrix $[\dot{D}]$ :

$$
[\dot{D}]=\left[\dot{d}_{i j}\right]_{i \times j}=\left(\begin{array}{ccc}
\left(\dot{\mu}_{11}, \dot{v}_{11}\right) & \ldots & \left(\dot{\mu}_{1 j}, \dot{v}_{1 j}\right) \\
\vdots & \ddots & \vdots \\
\left(\dot{\mu}_{i 1}, \dot{v}_{i 1}\right) & \cdots & \left(\dot{\mu}_{i j}, \dot{v}_{i j}\right)
\end{array}\right)
$$

\subsection{Core step}

Suppose there are $n$ known membership degree points $\left(\mu_{1}, \mu_{2}, \ldots, \mu_{n}\right) \in E$, where $E$ is the bounded closed box in $\mathrm{R}^{N}$ having length $l$. The corresponding positive weights of these points are $\xi_{1}, \xi_{2}, \ldots, \xi_{n}$. To search the optimal rally point $\dot{\mu}$, the core steps of PGSA are as follows.

Step 1:Determine the initial growth point $x^{0} \in x$ and the step length $\lambda$ (it is set atl/200 in this study), where $x=\left(x_{1}, x_{2}, \ldots, x_{m}\right)$ is the vector group of box E. Set $X_{\min }=x^{0}, F_{\min }=f\left(x^{0}\right)$, where $f\left(x^{0}\right)$ is the backlight function of $x^{0}$.

Step 2: Set $x^{0}$ as the thought center, draw line segments parallel to the $\mathrm{x}$ axis and $\mathrm{y}$ axis, and then extend $a_{1} \leq x_{1}^{0} \leq b_{1}, a_{2} \leq x_{2}^{0} \leq b_{2}, \ldots, a_{m} \leq x_{m}^{0} \leq b_{m}$ as new branches. Search $S_{i_{1} j_{1}}^{0}\left(1 \leq i_{1} \leq m, 1 \leq j_{1} \leq k_{1}\right)$ from the branches in $\lambda$, where $S_{i_{1} j_{1}}^{0}$ is the $j_{1}$ th growth point in the $i_{1}$ th branch.

Step 3: Compare $f\left(S_{i_{1} j_{1}}^{0}\right)$ and $F_{\text {min }}$. If $f\left(S_{i_{1} j_{1}}^{0}\right) \leq F_{\min }$, then $X_{\text {min }}=S_{i_{1} j_{1}}^{0}, F_{\text {min }}=f\left(S_{i_{1} j_{1}}^{0}\right)$.

Otherwise, keep $X_{\min }$ and $F_{\min }$ unchanged.

Step 4: If $f\left(x^{0}\right) \leq f\left(S_{i_{1} j_{1}}^{0}\right)$, then its growth hormone concentration is $C_{S_{i, j}^{0}}=0$; otherwise, employ Eq.(24) to calculate $C_{S_{\mathrm{ihi}^{0}}}$ :

$$
C_{S_{i_{11}}^{0}}=\frac{f\left(x^{0}\right)-f\left(S_{i_{1} j_{1}}^{0}\right)}{\sum_{i_{1}=1}^{m} \sum_{j_{1}=1}^{k_{1}}\left[f\left(x^{0}\right)-f\left(S_{i_{1} j_{1}}^{0}\right)\right]}
$$

Step 5: Use the growth hormone concentrations of all the growth points to establish a morphactin concentration state map between 0 and 1 . A random number $\delta_{0}$ is selected in this interval, if 


$$
\sum_{i_{1}=1}^{r_{1}} \sum_{j_{1}=1}^{t_{1}-1} C_{S_{i_{1}}^{0}}<\delta_{0} \leq \sum_{i_{1}=1}^{r_{1}} \sum_{j_{1}=1}^{t_{1}} C_{S_{h_{1}}^{0}}
$$

Then, select $S_{r_{1} t_{1}}^{0}$ as the new growth point; set $x^{1}=S_{r_{1} t_{1}}^{0}, X_{\text {min }}=x^{1}$, and $F_{\min }=f\left(x^{1}\right)$.

Step 6: Set $x^{1}$ as the thought center, draw line segments parallel to the $\mathrm{x}$ axis and $\mathrm{y}$ axis, and then extend $a_{1} \leq x_{1}^{1} \leq b_{1}, a_{2} \leq x_{2}^{1} \leq b_{2}, \ldots, a_{m} \leq x_{m}^{1} \leq b_{m}$ as new branches. Search $S_{i_{1} j_{1}}^{1}\left(1 \leq i_{2} \leq m, 1 \leq j_{2} \leq k_{1}\right)$ in the branches in $\lambda$.

Step 7: Compare $f\left(S_{i_{2} j_{2}}^{1}\right)$ and $F_{\min }$. If $f\left(S_{i_{2} j_{2}}^{1}\right) \leq F_{\min }$, then $X_{\min }=S_{i_{2} j_{2}}^{1}, F_{\min }=f\left(S_{i_{2} j_{2}}^{1}\right)$ and $F_{\min }$. Otherwise, keep $X_{\min }$ and $F_{\min }$ unchanged.

Step 8: Calculate $C_{S_{i, j}^{0}}$ and $C_{S_{i, j}^{1}}$.

If $f\left(x^{0}\right) \leq f\left(S_{i_{1} j_{1}}^{1}\right)$, then $C_{S_{i j 1}^{0}}=0$; otherwise, employ Equation (28) to calculate $C_{S_{i j i}^{0}}$ :

$$
C_{S_{i, 1}^{0}}=\frac{f\left(x^{0}\right)-f\left(S_{i_{1} j_{1}}^{0}\right)}{\sum_{i_{1}=1}^{m} \sum_{j_{1}=1}^{k_{1}}\left[f\left(x^{0}\right)-f\left(S_{i_{1} j_{1}}^{0}\right)\right]+\sum_{i_{1}=1}^{m} \sum_{j_{1}=1}^{k_{2}}\left[f\left(x^{0}\right)-f\left(S_{i_{2} j_{2}}^{1}\right)\right]}
$$

If $f\left(x^{0}\right) \leq f\left(S_{i_{2} j_{2}}^{1}\right)$, then $C_{S_{i, 2}^{1}}=0$; otherwise, employ Equation (29) to calculate $C_{S_{i, 2}^{1}}$ :

$$
C_{S_{i, 2}^{1}}=\frac{f\left(x^{0}\right)-f\left(S_{i_{2} j_{2}}^{1}\right)}{\sum_{i_{1}=1}^{m} \sum_{j_{1}=1}^{k_{1}}\left[f\left(x^{0}\right)-f\left(S_{i_{1} j_{1}}^{0}\right)\right]+\sum_{i_{1}=1}^{m} \sum_{j_{1}=1}^{k_{2}}\left[f\left(x^{0}\right)-f\left(S_{i_{2} j_{2}}^{1}\right)\right]}
$$

Step 9: Use the growth hormone concentrations of all the growth points to establish a morphactin concentration state map between 0 and 1 . A random number $\delta_{1}$ is selected in this interval. If

$$
\sum_{i_{1}=1}^{r_{2}} \sum_{j_{1}=1}^{t_{2}-1} C_{S_{i_{1}}^{0}}<\delta_{1} \leq \sum_{i_{1}=1}^{r_{2}} \sum_{j_{1}=1}^{t_{2}} C_{S_{i_{1}}^{0}}
$$

then select $S_{r_{1} t_{1}}^{0}$ as the new growth point, where set $x^{2}=S_{r_{1} t_{1}}^{0}, X_{\min }=x^{2}$ and $F_{\min }=f\left(x^{2}\right)$; otherwise, if

$$
\sum_{i_{1}=1}^{m} \sum_{j_{1}=1}^{k_{1}} C_{S_{i_{1 j}}^{0}}+\sum_{i_{1}=1}^{r_{2}} \sum_{j_{1}=1}^{t_{2}-1} C_{S_{i, j_{2}}^{1}}<\delta_{1} \leq \sum_{i_{1}=1}^{m} \sum_{j_{1}=1}^{k_{1}} C_{S_{i j_{1}}^{0}}+\sum_{i_{1}=1}^{r_{2}} \sum_{j_{1}=1}^{t_{2}} C_{S_{i, j_{2}, 2}^{1}},
$$

then select

$S_{r_{2} t_{2}}^{1}$ as the new growth point, where $x^{2}=S_{r_{1} t_{1}}^{1}, X_{\min }=x^{2}$, and $F_{\min }=f\left(x^{2}\right)$ are set. Step 10: Repeat Steps 6 to 9, until $F_{\min }$ remains unchanged. Then, $x^{*}=X_{\min }$ is the globally optimal solution; set $\dot{\mu}=x^{*}$, and the calculation is stopped.

\section{Illustrative example}

In this section, the performance of the proposed method is evaluated according to a case that was first presented by Herrera and then modified by $\mathrm{Xu}[25]$. 


\subsection{Experimental process and result}

Suppose that an individual intends to buy a car.Expert $e_{k}(k=1,2,3,4)$ uses IVIFN $\tilde{d}_{i j}^{k}(i, j=1,2,3,4,5)$ to describe the characteristics $C_{j}(j=1,2,3,4,5)$ of each supplier. $A_{i}=(i=1,2,3,4,5)$, the weight vector of four experts is $\zeta=(0.3,0.2,0.3,0.2)^{\mathrm{T}}$, and the weight vector of five characteristics is $\omega=(0.2,0.15,0.2,0.3,0.15)^{\mathrm{T}}$.

Step 1.The IVIF decision matrices proposed by four experts $\tilde{D}_{k}=\left[\tilde{d}_{i j}^{(k)}\right]_{5 \times 5}(k=1,2,3,4)$ are indicated as

$$
\begin{aligned}
& \begin{array}{lllll}
\mathrm{C}_{1} & \mathrm{C}_{2} & \mathrm{C}_{3} & \mathrm{C}_{4} & \mathrm{C}_{5}
\end{array}
\end{aligned}
$$

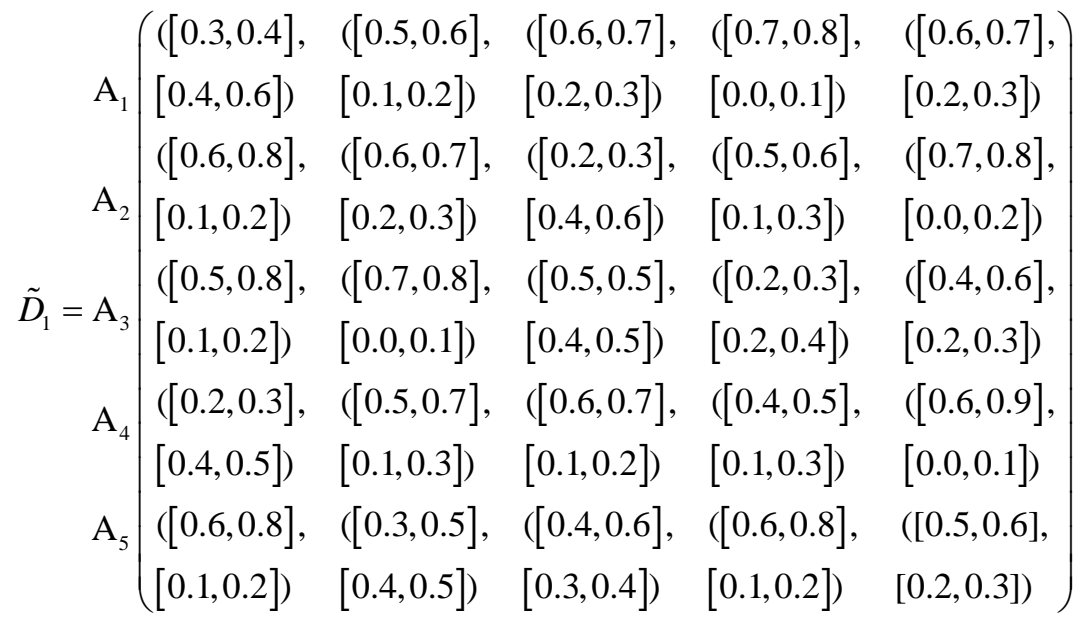

$$
\begin{aligned}
& \begin{array}{lllll}
\mathrm{C}_{1} & \mathrm{C}_{2} & \mathrm{C}_{3} & \mathrm{C}_{4} & \mathrm{C}_{5}
\end{array}
\end{aligned}
$$

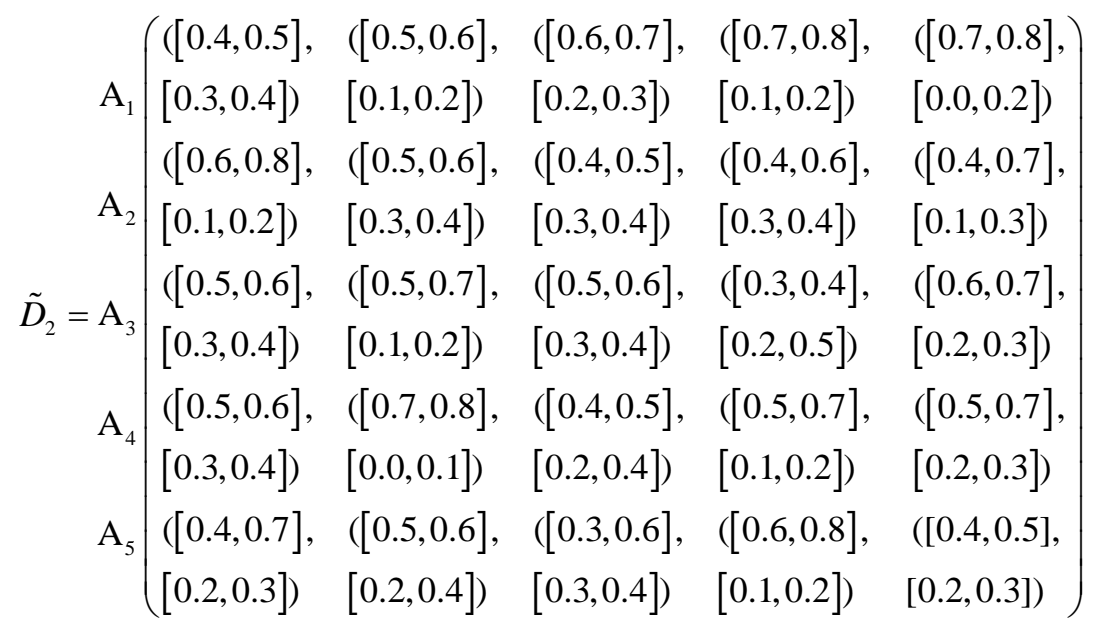




$$
\begin{aligned}
& \begin{array}{llllll}
\mathrm{C}_{1} & \mathrm{C}_{2} & \mathrm{C}_{3} & \mathrm{C}_{4} & \mathrm{C}_{5}
\end{array}
\end{aligned}
$$

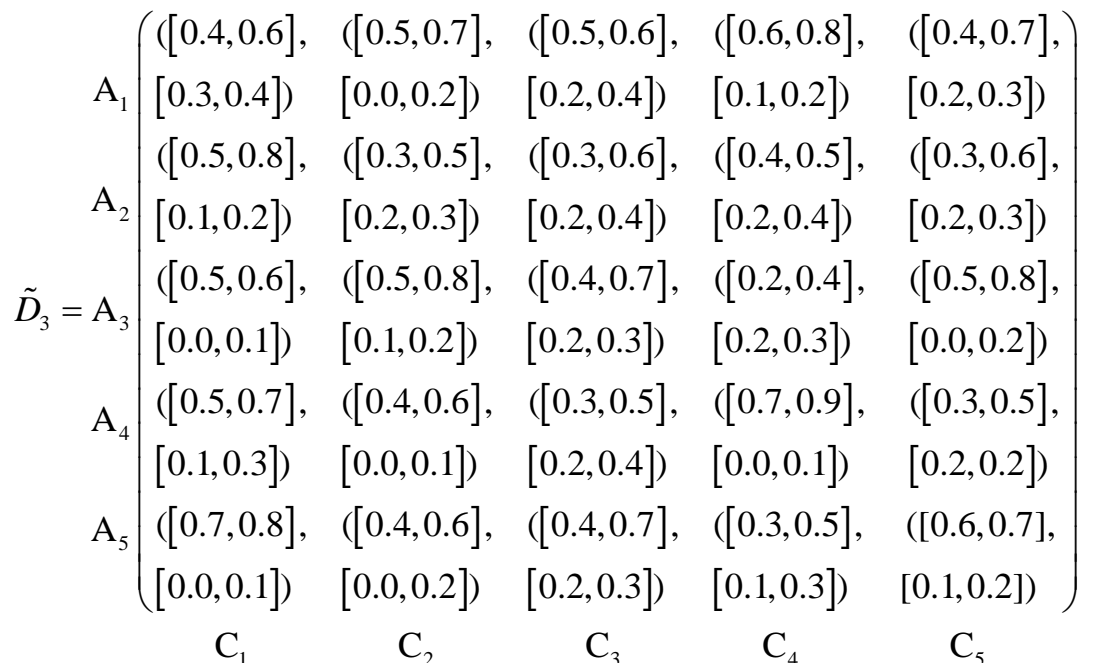

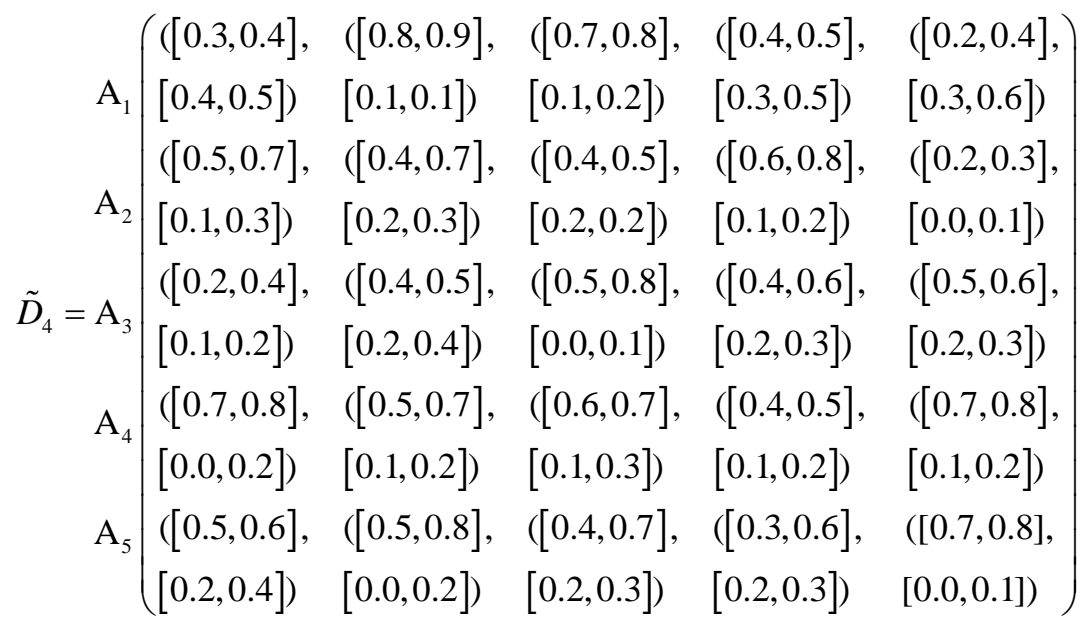

Step2.Map the interval-valued membership degree numbers and non-membership degree numbers into two-dimensional coordinates and employ PGSA to aggregate the expert preference decision matrices into the collective matrix $\dot{D}$ : 


$$
\begin{aligned}
& \begin{array}{lllll}
\mathrm{C}_{1} & \mathrm{C}_{2} & \mathrm{C}_{3} & \mathrm{C}_{4} & \mathrm{C}_{5}
\end{array}
\end{aligned}
$$

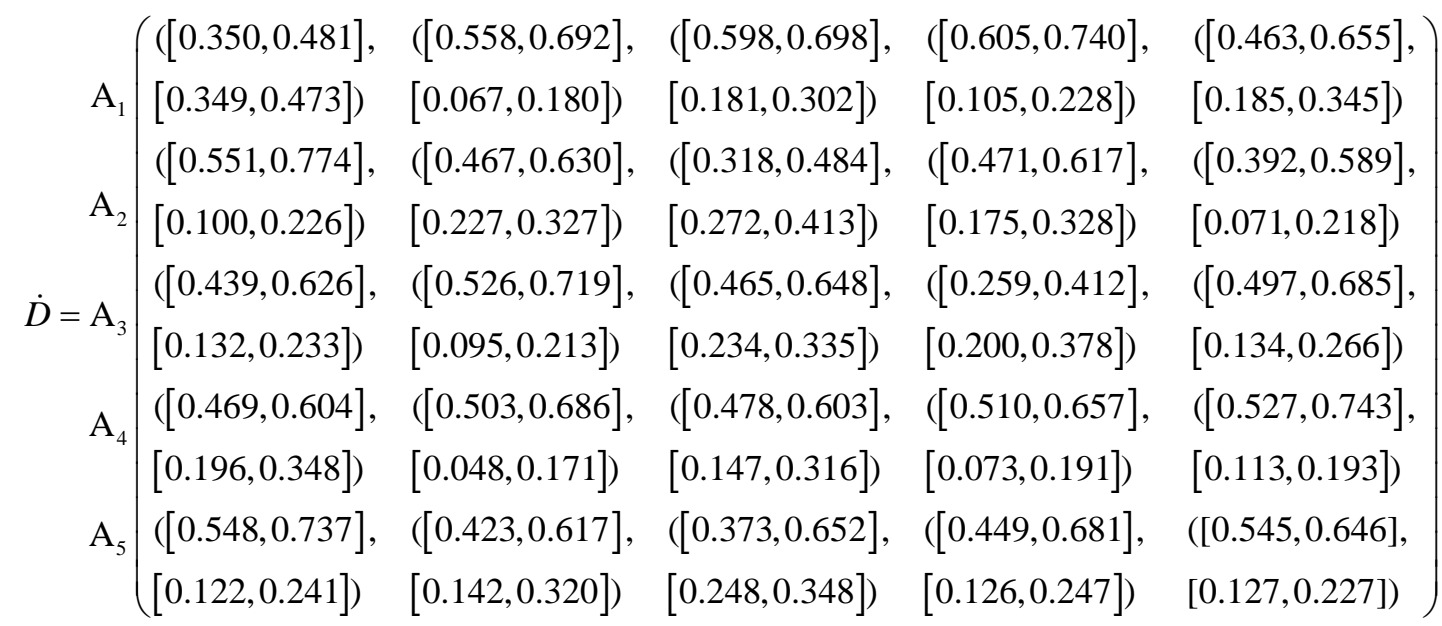

Step3. Obtain the comprehensive attribute matrix $\dot{\tilde{D}}$ by using the IIFWA operator to separately aggregate the data on each line in $\dot{D}$ :

$$
\left.\begin{array}{rr|rl} 
& \mathrm{A}_{1} & ([0.5335,0.6710],[0.1516,0.2865]) \\
& \mathrm{A}_{2} & ([0.4494,0.6321],[0.1552,0.3000]) \\
\dot{\tilde{D}}=\mathrm{A}_{3} & ([0.4206,0.6048],[0.1599,0.2915]) \\
& \mathrm{A}_{4} & ([0.4972,0.6564],[0.1025,0.2345]) \\
& \mathrm{A}_{5} & ([0.4682,0.6740],[0.1462,0.2702])
\end{array}\right)
$$

Step4. Employ Eq. (14) to obtain the alternatives' scores $S\left(\tilde{A}_{i}\right)(i=1,2,3,4,5)$ :

$S\left(\tilde{A}_{1}\right)=0.383106, S\left(\tilde{A}_{2}\right)=0.31315, S\left(\tilde{A}_{3}\right)=0.286989, S\left(\tilde{A}_{4}\right)=0.4083, S\left(\tilde{A}_{5}\right)=0.362932$,

Thus,

$A_{4} \succ A_{1} \succ A_{5} \succ A_{2} \succ A_{3}$

Therefore, the best alternative is $A_{4}$.

The experiment is iterated 900 times. Fig. 7 shows the simulation curve of $\hat{d}(\dot{D}), \hat{S}(\dot{D})$, $\hat{K}(\dot{D})$, and $E(\dot{D})$.

In Fig. 7(a), the red solid line denotes the total weighted Hamming distance between the collctive matrix and expert preference matrices, and the blue dotted line denotes the distance is 2.94 when the number of iterations is 700 . In the subsequent iterations, the distance converges roughly, which means that the proposed algorithm obtains the optimal collective matrix. Fig. 7(b) denotes the energy of collective matrix and Fig. 7(a) denotes the total similarity measure (red solid line) and the total correlation coefficient (blue solid line) between the collctive matrix and expert preference matrices. The blue dotted lines denote their convergent values, resprctively. The conclusion of Fig. 7(a) is demonstrated from Fig. 7(b) and Fig. 7(c). 


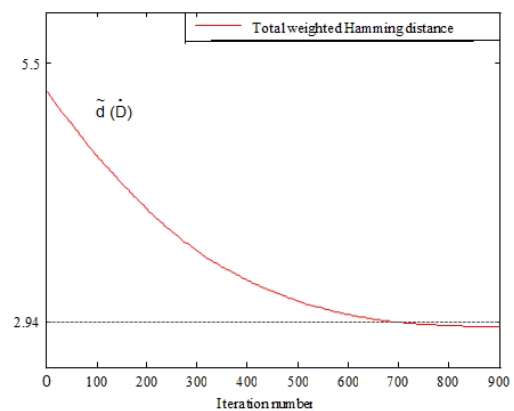

Fig. 7(a). Simulation curve of $\hat{d}(\dot{D})$

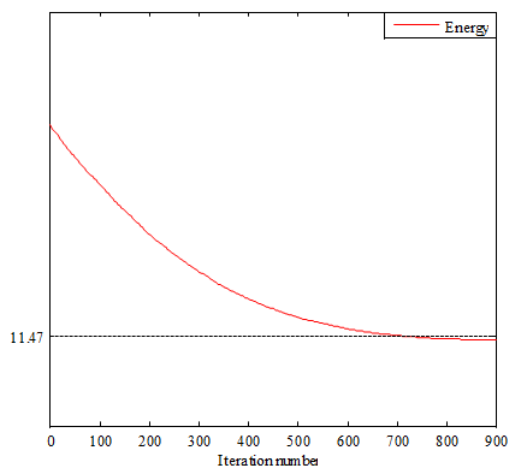

Fig. 7(b). Simulation curve of $\hat{S}(\dot{D})$

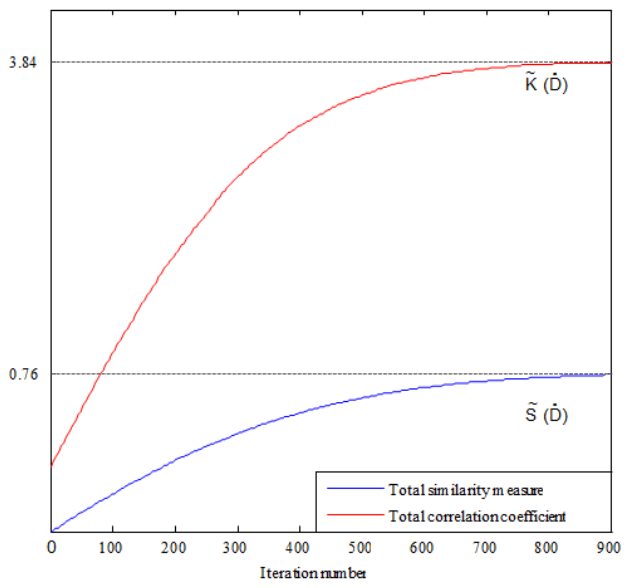

Fig. 7(c). Simulation curve of $\hat{K}(\dot{D})$, and $E(\dot{D})$

\subsection{Accuracy comparison}

The PGSA method, the IIFHA operator, the IIFHG operator, and a group decision-making method proposed by Ye [3] were respectively employed to solve the same example. Then, different results were obtained:

(1) PGSA: $A_{4} \succ A_{1} \succ A_{5} \succ A_{2} \succ A_{3}$;

(2) IIFHA: $A_{1} \succ A_{4} \succ A_{5} \succ A_{2} \succ A_{3}$;

(3) IIFHG: $A_{4} \succ A_{1} \succ A_{5} \succ A_{2} \succ A_{3}$; 
(4) The method proposed by Ye: $A_{5} \succ A_{4} \succ A_{1} \succ A_{2} \succ A_{3}$.

Then, Eqs. (19)-(22) are employed to calculate $\hat{d}(\dot{D}), \hat{S}(\dot{D}), \hat{K}(\dot{D})$, and $E(\dot{D})$ of the collective matrices established by the different methods (see Table 1).

Table 1. Accuracy comparison

\begin{tabular}{|c|c|c|c|c|}
\hline \hline & $\hat{d}(\dot{D})$ & $\hat{S}(\dot{D})$ & $\hat{K}(\dot{D})$ & $E(\dot{D})$ \\
\hline PGSA & 2.948834 & 0.7631189 & 3.89039071 & 11.47649 \\
\hline IIFHA & 3.29775 & 0.75861615 & 3.85841822 & 12.30863 \\
\hline IIFHG & 2.967163 & 0.75980447 & 3.88809729 & 11.40351 \\
\hline Ye's method & 3.48762 & 0.71467303 & 3.83492642 & 12.50786 \\
\hline
\end{tabular}

The table shows that the orders of the programs obtained by PGSA and IIFHG are more credible, than those of the other methods. PGSA is more accurate than IIFHG and IIFHG is less fuzzy than PGSA.

\section{Conclusion}

A novel evaluation criterion for judging the accuracy of results in an MAGDM problem with IVIFN information is proposed in this paper. Different aggregation methods are suitable for different cases. The proposed criterion is able to select the best aggregation method easily, when the aggregation results are different. In addition, in this paper, a PGSA is proposed to solve an MAGDM problem with IVIFN information, which employs optimal rally points to establish the collective matrix and obtain a more accurate result compared with the typical methos. All these procedures are illustrated using a classical example that was first presented by Herrera.

\section{References}

[1] S.P. Wan, J.Y. Dong, "Multi-Attribute Group Decision Making with Trapezoidal Intuitionistic Fuzzy Numbers and Application to Stock Selection,” Informatica, vol. 25, no. 4, pp.663-697, 23-27, 2015.Article (CrossRef Link)

[2] X.W. Qi, C.Y. Liang, J.L. Z, "Generalized cross-entropy based group decision making with unknown expert and attribute weights under interval-valued intuitionistic fuzzy environment," Computers \& Industrial Engineering, vol. 79, pp. 52-64, 2015. Article (CrossRef Link)

[3] J.Ye, "Multiple Attribute Group Decision-Making Methods with Completely Unknown Weights in Intuitionistic Fuzzy Setting and Interval-Valued Intuitionistic Fuzzy Setting,” Journal of Intelligent \& Fuzzy Systems, vol. 22, no.5, pp. 173-188, 2013. Article (CrossRef Link)

[4] Z.L. Yue, "An extended TOPSIS for determining weights of decision makers with interval numbers,” Knowledge-based Systems, vol. 24, no.1, pp. 146-153, 2011. Article (CrossRef Link)

[5] S Prakash, RB Patel , VK Jain, “A Multi-Attribute Intuitionistic Fuzzy Group Decision Method For Network Selection In Heterogeneous Wireless Networks Using TOPSIS,” KSII Transactions on Internet \& Information Systems, vol. 10, no.11, pp. 5229-5252, 2016. Article (CrossRef Link)

[6] W. Liu, L. Li, "An approach to determining the integrated weights of decision makers based on interval number group decision matrices,” Knowledge-based Systems, vol. 90, no.C, pp. 92-98, 2015. Article (CrossRef Link)

[7] P. Borkar, “Acoustic Signal based Optimal Route Selection Problem: Performance Comparison of Multi-Attribute Decision Making methods,” KSII Transactions on Internet \& Information Systems, vol. 10, no.2, pp. 647-669, 2016. Article (CrossRef Link) 
[8] Y. Li, Y. Wang, and P. Liu, "Multiple attribute group decision-making methods based on trapezoidal fuzzy two-dimension linguistic power generalized aggregation operators," Soft Computing, vol. 20, no.7, pp. 1-16, 2016. Article (CrossRef Link)

[9] X Liu, Y Ju, and S Yang, "Some generalized interval-valued hesitant uncertain linguistic aggregation operators and their applications to multiple attribute group decision making," Soft Computing, vol. 20, no.2, pp. 1-16, 2016. Article (CrossRef Link)

[10] L. Rui, Y. Zhang, H.Q. Huang, and et al, “A New Traffic Congestion Detection and Quantification Method Based on Comprehensive Fuzzy Assessment in VANET,” KSII Transactions on Internet \& Information Systems, vol. 12, no.1, pp. 41-60, 2018. Article (CrossRef Link)

[11] Z.L. Mei, B. Wu, S.L. Tian, and et al, "Fuzzy Keyword Search Method over Ciphertexts supporting Access Control,” KSII Transactions on Internet \& Information Systems, vol. 11, no.11, pp. 5671-5693, 2017. Article (CrossRef Link)

[12] B.M. Chang, "Design of Solving Similarity Recognition for Cloth Products Based on Fuzzy Logic and Particle Swarm Optimization Algorithm," KSII Transactions on Internet \& Information Systems, vol. 10, no.11, pp. 4967-4985, 2017. Article (CrossRef Link)

[13] S.D. Xian, Y.F. Dong, Y.B. Liu, “A Novel Approach for Linguistic Group Decision Making Based on Generalized Interval-Valued Intuitionistic Fuzzy Linguistic Induced Hybrid Operator and TOPSIS,” International Journal of Intelligent Systems, vol. 2, no.33, pp. 288-314, 2018. Article (CrossRef Link)

[14] J.D. Qiu, L. Li, “A new approach for multiple attribute group decision making with interval-valued intuitionistic fuzzy information,” Applied Soft Computing, vol. 20, no.2, pp. 1-16, 2016. DOI: http://dx.doi.org/doi:10.1016/j.asoc.2017.07.008. Article (CrossRef Link)

[15] S.P. Wan, J.Y. Dong, "Interval-valued intuitionistic fuzzy mathematical programming method for hybrid multi-criteria group decision making with interval-valued intuitionistic fuzzy truth degrees,” Information Fusion, vol. 26, no.C, pp. 49-65, 2015. Article (CrossRef Link)

[16] Z.S. Xu,J.Chen, “An overview of distance and similarity measures of intuitionistic fuzzy sets," International Journal of Uncertainty, Fuzziness and Knowledge-Based Systems, vol. 16, no.4, pp. 529-555, 2008. Article (CrossRef Link)

[17] H. Bustince, P. Burillo, "Correlation of interval-valued intuitionistic fuzzy sets," Fuzzy Sets and Systems, vol. 74, no.2, pp. 237-244, 1995. Article (CrossRef Link)

[18] G.P. Dong, Y.C. Kwun, H.P. Jin, I.Y. Park, "Correlation coefficient of interval-valued intuitionistic fuzzy sets and its application to multiple attribute group decision making problems," Mathematical and Computer Modelling, vol. 50, no.9-10, pp. 1279-1293, 2009. Article (CrossRef Link)

[19] Z.S. Xu, "Some similarity measures of intuitionistic fuzzy sets and their applications to multiple attribute decision making,” Fuzzy Optimization and Decision Making, vol. 6, no.2, pp. 109-121, 2007. Article (CrossRef Link)

[20] C. Wang, H.Z. Cheng, Z.C. Hu, Y Wang, "Distribution system optimization planning based on growth simulation algorithm,” Journal of Shanghai Jiaotong University, vol. 13, no.4, pp. 462-467, 2008. Article (CrossRef Link)

[21] T. Li, Z.T. Wang, "Application of plant growth simulation algorithm on solving facility location problem,” Systems Engineering-Theory \& Practice, vol. 28, no.12, pp. 107-115, 2008. Article (CrossRef Link)

[22] C. Wang, H.Z. Cheng, "Transmission network optimal planning based on plant growth simulation algorithm,” International Transactions on Electrical Energy Systems, vol. 19, no.2, pp. 291-301, 2009. Article (CrossRef Link)

[23] R.S. Rao, S.V.L. Narasimham, M. Ramalingaraju, “Optimal capacitor placement in a radial distribution system using plant growth simulation algorithm,” International Journal of Electrical Power \& Energy Systems, vol. 33, no.5, pp. 1133-1139, 2011. Article (CrossRef Link)

[24] S.L. Lu, S.Z. Yu, “A fuzzy k-coverage approach for RFID network planning using plant growth simulation algorithm,” Academic Press Ltd, vol. 39, no.1, pp. 280-291, 2014.

Article (CrossRef Link) 
[25] Z.S. Xu, “Intuitionistic Fuzzy Information Aggregation: Theory and Application,” Science Press, vol. 9, no.4, pp. 1-102, 2012. Article (CrossRef Link)

\section{Appendix}

Theorem 1.Let $\tilde{A}=\left\langle x, \mu_{\tilde{A}}(x), v_{\tilde{A}}(x)\right\rangle$ and $\tilde{B}=\left\langle x, \mu_{\tilde{B}}(x), v_{\tilde{B}}(x)\right\rangle$ be two IVIFSs in $X$, and $x \in X$. Then, we stipulate:

(1) $\tilde{A}^{c}=\left\{\left\langle x, v_{\tilde{A}}(x), \mu_{\tilde{A}}(x)\right\rangle\right\}$;

(2) $\tilde{A} \subseteq \tilde{B} \Leftrightarrow \mu_{\tilde{A}}^{L}(x) \leq \mu_{\tilde{B}}^{L}(x), \mu_{\tilde{A}}^{U}(x) \leq \mu_{\tilde{B}}^{U}(x)$, and $v_{\tilde{A}}^{L}(x) \geq v_{\tilde{B}}^{L}(x), v_{\tilde{A}}^{U}(x) \geq v_{\tilde{B}}^{U}(x)$;

(3) $\tilde{A}=\tilde{B} \Leftrightarrow \tilde{A} \subseteq \tilde{B}$ and $\tilde{A} \supseteq \tilde{B}$.

Theorem 2.Let $\tilde{A}=\left\langle x, \mu_{\tilde{A}}(x), v_{\tilde{A}}(x)\right\rangle$ and $\tilde{B}=\left\langle x, \mu_{\tilde{B}}(x), v_{\tilde{B}}(x)\right\rangle$ be two IVIFSs in $X$, where $x \in X$, and $\lambda>0$ and $m>0$. Then, the operational relations are defined as

$$
\begin{aligned}
& \tilde{A}+\tilde{B}=\left\{\left\langlex,\left[\mu_{\tilde{A}}^{L}(x)+\mu_{\tilde{A}}^{L}(x)-\mu_{\tilde{B}}^{L}(x) \cdot \mu_{\tilde{B}}^{L}(x),\right.\right.\right. \\
& \left.\mu_{\tilde{A}}^{U}(x)+\mu_{\tilde{B}}^{U}(x)-\mu_{\tilde{A}}^{U}(x) \cdot \mu_{\tilde{B}}^{U}(x)\right], \\
& \left.\left.\left[v_{\tilde{A}}^{L}(x) \cdot v_{\tilde{B}}^{L}(x), v_{\tilde{A}}^{U}(x) \cdot v_{\tilde{B}}^{U}(x)\right]\right\rangle\right\} . \\
& \tilde{A} \cdot \tilde{B}=\left\{\left\langlex,\left[\mu_{\tilde{A}}^{L}(x) \cdot \mu_{\tilde{B}}^{L}(x), \mu_{\tilde{A}}^{U}(x) \cdot \mu_{\tilde{B}}^{U}(x)\right],\right.\right. \\
& {\left[v_{\tilde{A}}^{L}(x)+v_{\tilde{B}}^{L}(x)-v_{\tilde{A}}^{L}(x) \cdot v_{\tilde{B}}^{L}(x),\right.} \\
& \left.\left.\left.v_{\tilde{A}}^{U}(x)+v_{\tilde{B}}^{U}(x)-v_{\tilde{A}}^{U}(x) \cdot v_{\tilde{B}}^{U}(x)\right]\right\rangle\right\} . \\
& \tilde{A} \cap \tilde{B}=\left\{\left\langlex,\left[\min \left\{\mu_{\tilde{A}}^{L}(x), \mu_{\tilde{B}}^{L}(x)\right\}, \min \left\{\mu_{\tilde{A}}^{U}(x), \mu_{\tilde{B}}^{U}(x)\right\}\right],\right.\right. \\
& \left.\left.\left[\max \left\{v_{\tilde{A}}^{L}(x), v_{\tilde{B}}^{L}(x)\right\}, \max \left\{v_{\tilde{A}}^{U}(x), v_{\tilde{B}}^{U}(x)\right\}\right]\right\}\right\} . \\
& \tilde{A} \cup \tilde{B}=\left\{\left\langlex,\left[\max \left\{\mu_{\tilde{A}}^{L}(x), \mu_{\tilde{B}}^{L}(x)\right\}, \max \left\{\mu_{\tilde{A}}^{U}(x), \mu_{\tilde{B}}^{U}(x)\right\}\right],\right.\right. \\
& \left.\left.\left[\min \left\{v_{\tilde{A}}^{L}(x), v_{\tilde{B}}^{L}(x)\right\}, \min \left\{v_{\tilde{A}}^{U}(x), v_{\tilde{B}}^{U}(x)\right\}\right]\right\rangle\right\} \\
& \lambda \tilde{A}=\left\{\left\langlex,\left[1-\left(1-\mu_{\tilde{A}}^{L}(x)\right)^{\lambda}, 1-\left(1-\mu_{\tilde{A}}^{U}(x)\right)^{\lambda}\right],\right.\right. \\
& \left.\left.\left[\left(v_{\tilde{A}}^{L}(x)\right)^{\lambda},\left(v_{\tilde{A}}^{U}(x)\right)^{\lambda}\right]\right\rangle\right\} \text {. } \\
& \tilde{A}^{\lambda}=\left\{\left\langlex,\left[\left(\mu_{\tilde{A}}^{L}(x)\right)^{\lambda},\left(\mu_{\tilde{A}}^{U}(x)\right)^{\lambda}\right],\right.\right. \\
& \left.\left.\left[1-\left(1-v_{\tilde{A}}^{L}(x)\right)^{\lambda}, 1-\left(1-v_{\tilde{A}}^{U}(x)\right)^{\lambda}\right]\right\rangle\right\} \text {. }
\end{aligned}
$$




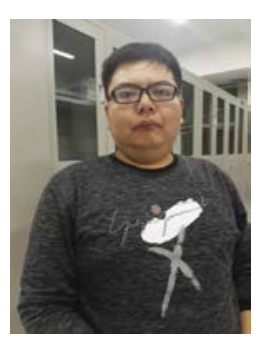

Junda Qiu was born in 1990. He received his M.S. degree in computer science and technology from Guangxi Teachers Education Universtiy in 2015. He is currently a Ph.D. candidate at the School of Internet of Things Engineering in Jiangnan University. His research interests include fuzzy set, group decision making and data mining.

E-mail: junda.qiu@foxmail.com

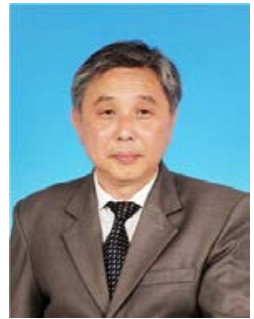

Lei Li was born in 1959. He received the Ph.D. degree in management science from Tianjin University in 2004 and entried to post doctoral mobile station of civil engineering of Harbin Institute of Technology in 2005. Currently, he is a professor and Ph.D. supervisor in the School of Internet of Things Engineering in Jiangnan University. His reserach interests include optimization theory and application, group decision making and artificial intelligence.

E-mail: inf2007@126.com 